\title{
IAG Newsletter
}

\author{
Gyula Tóth ${ }^{1}$
}

(c) Springer-Verlag GmbH Germany, part of Springer Nature 2021

The IAG Newsletter is under the editorial responsibility of the Communication and Outreach Branch (COB) of the IAG. It is an open forum, and contributors are welcome to send material (preferably in electronic form) to the IAG COB. These contributions should complement information sent by IAG officials or by IAG symposia organizers (reports and announcements). The IAG Newsletter is published monthly. It is available in different formats from the IAG internet site: http://www.iag-aig.org.

Each IAG Newsletter includes several of the following topics:

I. General information

II. Reports of IAG symposia

III. Reports by commissions, special commissions or study groups

IV. Symposia announcements

V. Book reviews

VI. Fast bibliography

\section{Reports}

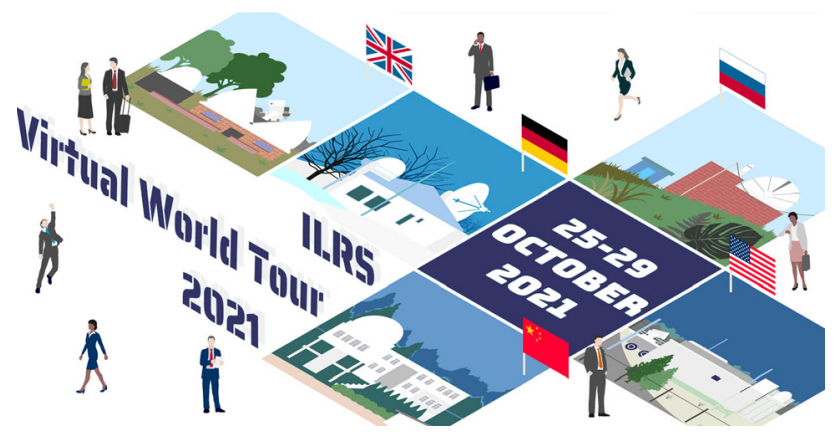

Gyula Tóth

toth.gyula@emk.bme.hu

http://www.iag-aig.org/

1 Department of Geodesy and Surveying, IAG Communication and Outreach Branch, Budapest University of Technology and Economics, Budapest 1521, Hungary
ILRS Virtual World Tour 2021

Online event, 25-29 October 2021

Website: https://ilrs.gsfc.nasa.gov/ILRS_Virtual_World_ Tour_2021/index.html

Once again, the International Laser Ranging Service (ILRS) had to postpone its 22nd International Workshop on Laser Ranging in Kunming, originally scheduled for 2020, due to the coronavirus pandemic. Following the successful first attempt last year (see the December 2020 issue of IAG Newsletter), we organized the second round of ILRS Virtual World Tour this year, while awaiting the opportunity to continue our Workshop tradition.

This year, the host stations were: Herstmonceux (United Kingdom), Wettzell (Germany), Mendeleevo (and shortly Irkutsk; both Russia), Shanghai (China) and Monument Peak (USA). All of the Microsoft Teams sessions were hosted by CDDIS/NASA. The participants could virtually visit these five stations and have technical and casual chats with the local colleagues for 1 or $2 \mathrm{~h}$. The sessions were the mixture of pre-recorded movies and live discussions, and we are amazed not only at their latest developments presented by the stations, but also at the high quality of movies, narrations and even live music. In addition, we organized special sessions before or after the station visits that offered the latest updates from each component of the ILRS, such as missions, analysis, network \& engineering, lunar ranging, space debris ranging, and format and procedures. In the opening session, for example, our worldwide operations through the pandemic period were praised by Basara Miyahara, the GGOS President, and Frank Lemoine gave a nice presentation on how our precise laser ranging observations are contributing to the monitoring of global warming. All of the virtual tour and session scenes were recorded and will be uploaded to the event website hosted by CDDIS/NASA. We very much appreciate the contributions from all of the presenters, video editors and participants; they certainly made this event a great success. 
We hope to see attendees face to face in Kunming next year. The dates are already set: 31 October -4 November 2022.

Toshimichi Otsubo

Hitotsubashi University

On behalf of the organizing team (T. Otsubo, C. Carabajal, E. Hoffmann, I. Ignatenko, J. Laing, M. Pearlman, U. Schreiber and Z. Zhongping), the host institutes and the special session chairs.

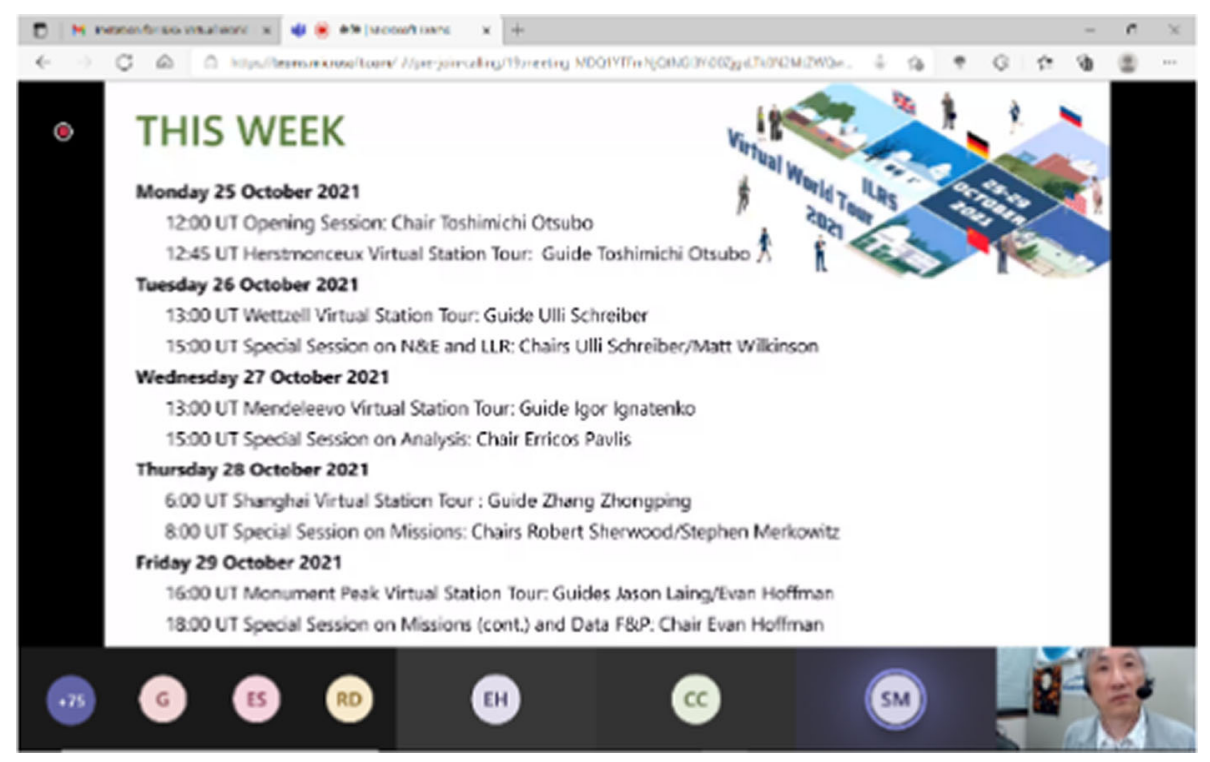

Screenshot 1: The plan of the week.

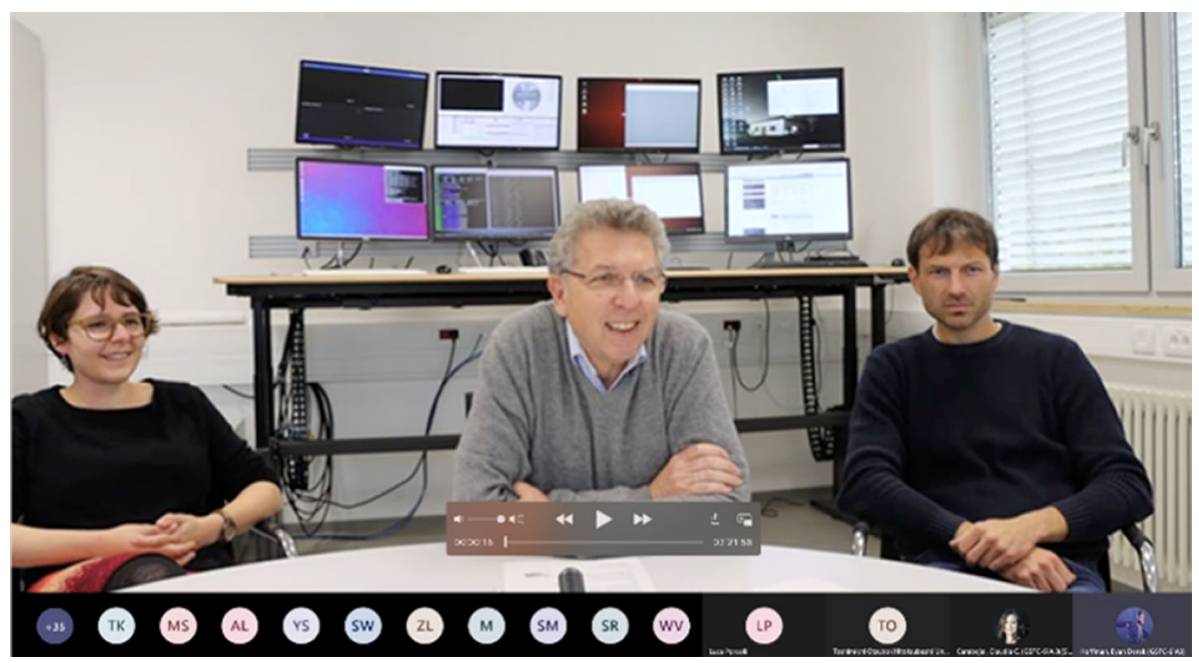

Screenshot 2: Tour of Wettzell. Q\&A session. 


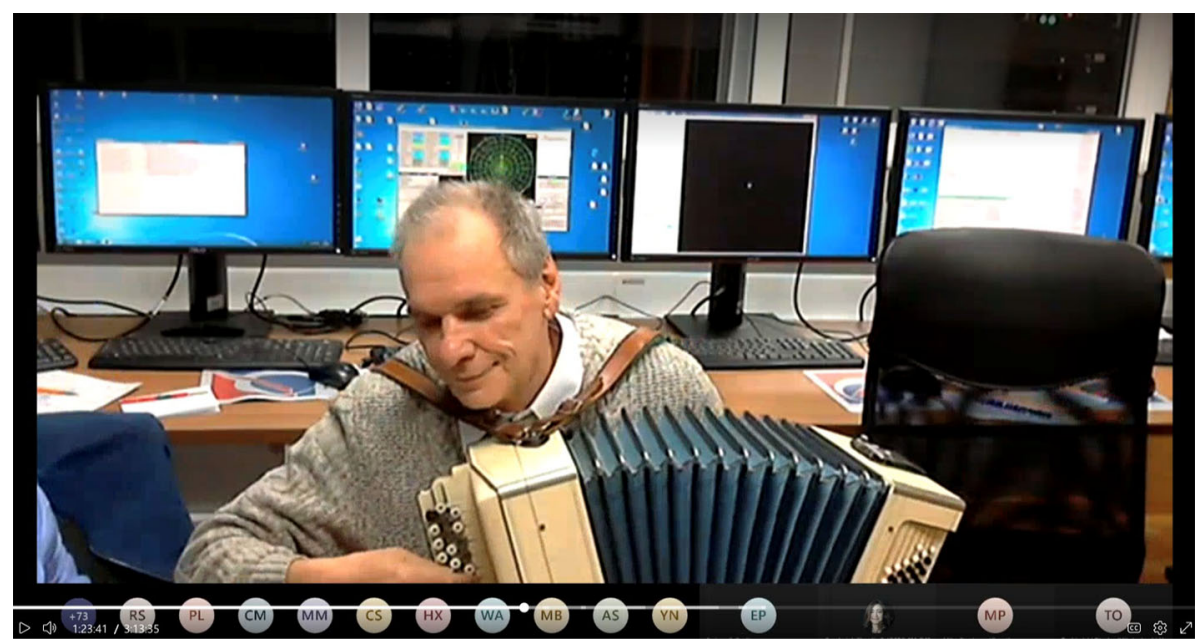

Screenshot 3: Tour of Mendeleevo. Entertainment time.

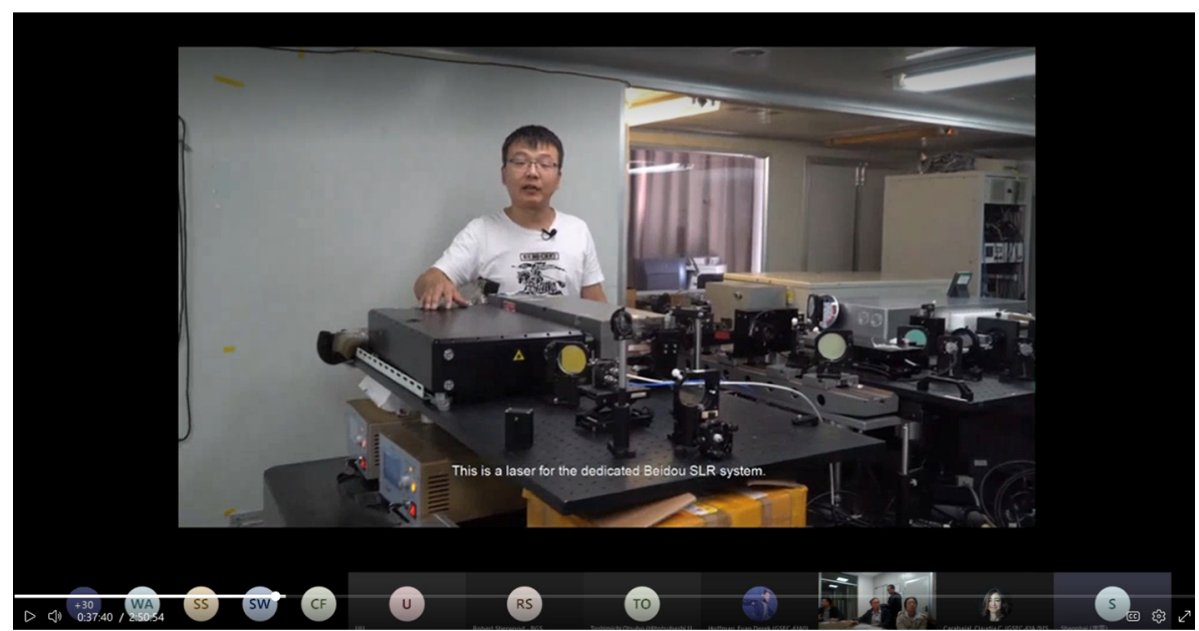

Screenshot 4: Tour of Shanghai. Visiting the Laser room. 